Research paper

\title{
Alginate hydrogel improves anti-angiogenic bevacizumab activity in cancer therapy
}

\author{
Natália N. Ferreira ${ }^{a}$, Leonardo M.B. Ferreira ${ }^{a}$, Vera Miranda-Gonçalves ${ }^{\text {b,c }}$, Rui M. Reis ${ }^{\text {b,c,d }}$,

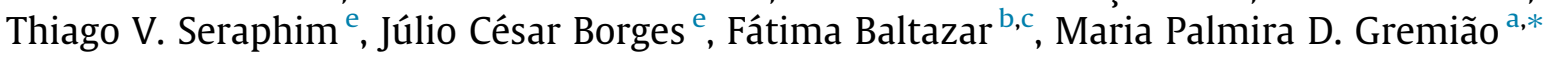 \\ a School of Pharmaceutical Science, São Paulo State University, UNESP, Rodovia Araraquara/Jaú km 1, Araraquara, São Paulo, Brazil \\ ${ }^{\mathrm{b}}$ Life and Health Sciences Research Institute (ICVS), School of Medicine, University of Minho, Braga, Portugal \\ 'ICVS/3B's-PT Government Associate Laboratory, Braga/Guimarães, Portugal \\ ${ }^{\mathrm{d}}$ Molecular Oncology Research Center, Barretos Cancer Hospital, São Paulo, Brazil \\ e Institute of Chemistry of São Carlos, University of São Paulo, USP, São Carlos, Brazil
}

\section{A R T I C L E I N F O}

Article history:

Received 15 September 2016

Revised 9 April 2017

Accepted in revised form 28 June 2017

Available online 29 June 2017

\section{Chemical Compounds:}

Alginate sodium salt (PubChem CID

91666323)

Calcium chloride (PubChem CID5284359)

Sodium chloride (PubChem CID5234)

Lactic acid (PubChem CID612)

Dibasic sodium phosphate (PubChem CID

24203)

Hydrochloric acid (PubChem CID 313)

Sodium hydroxide (PubChem CID 14798)

Keywords:

Protein delivery system

Bevacizumab

Calcium alginate hydrogel

Tumor microenvironment

Supramolecular interactions

\begin{abstract}
A B S T R A C T
Anti-vascular endothelial growth factor (anti-VEGF) therapy applied to solid tumors is a promising strategy, yet, the challenge to deliver these agents at high drug concentrations together with the maintenance of therapeutic doses locally, at the tumor site, minimizes its benefits. To overcome these obstacles, we propose the development of a bevacizumab-loaded alginate hydrogel by electrostatic interactions to design a delivery system for controlled and anti-angiogenic therapy under tumor microenvironmental conditions. The tridimensional hydrogel structure produced provides drug stability and a system able to be introduced as a flowable solution, stablishing a depot after local administration. Biological performance by the chick embryo chorioallantoic membrane (CAM) assay indicated a pH-independent improved anti-angiogenic activity $(\sim 50 \%)$ compared to commercial available anti-VEGF drug. Moreover, there was a considerable regression in tumor size when treated with this system. Immunohistochemistry highlighted a reduced number and disorganization of microscopic blood vessels resulting from applied therapy. These results suggest that the developed hydrogel is a promising approach to create an innovative delivery system that offers the possibility to treat different solid tumors by intratumoral administration.
\end{abstract}

(c) 2017 Elsevier B.V. All rights reserved.

\section{Introduction}

Cancer is one of the most aggressive diseases leading to death worldwide [1]. Despite all scientific knowledge and advances in therapeutic discovery, the inability of drugs to reach the target site of action by systemic delivery appears to be the major drawback needing a denouement [2]. High doses of therapeutic agents lead to unwanted side effects or toxicity in addition to compromising patients' quality of life [3]. Notwithstanding, a great attention

\footnotetext{
* Corresponding author at: School of Pharmaceutical Science, São Paulo State University, UNESP, Rodovia Araraquara-Jaú Km 01, Araraquara, SP 14801-902. Brazil.

E-mail address: pgremiao@fcfar.unesp.br (M.P.D. Gremião).
}

has been given towards the development of delivery systems, useful to provide sufficient quantities of drug at the target tissues, besides extended or controlled release of these pharmaceutical agents $[2,4-6]$.

Anti-VEGF therapy based on the monoclonal antibody (mAb) bevacizumab (BVZ) is a promising strategy for solid tumor treatment since cancer initiation, growth and progression requires the occurrence of angiogenesis, what ensures a nutritional and respiratory cell support [7-11]. However, clinical trials failed to demonstrate encouraging results and, therefore, few FDA approved protocols were established on its use alone or associated with chemotherapeutic agents [12]. On the other hand, the use of BVZ therapy for macular degeneration and diabetic retinopathy, has received attention [13-16]. The spectrum of ocular diseases trea- 
ted by anti-VEGF therapy demonstrated a remarkable advancement when locally administered by intravitreal injections, in an attempt to reach deeper eye areas [14]. Although its use appears to avoid adverse side effects associated to systemic administration, successful treatment requires high frequency of injections due the limited drug half-life in the vitreous [2]. To overcome this limitation, a series of implantable or injectable BVZ delivery systems have been developed ensuring the increased concentration gradient, improving drug effect [2,17-19].

Whilst the extended serum half-life of BVZ [13] seems to support the limited attention focused on delivery systems applied to anti-VEGF cancer therapy, other issues should be accounted for [20]. As a protein macromolecule, BVZ exhibits a complex threedimensional structure hindering its permeation through biological membranes [21]. Moreover, they display physicochemical instability and susceptibility to environmental factors, conditions that might be outlined by local delivery system technology through intratumoral injections [21,22]. Besides, localized therapy applied to cancer became particularly attractive when tumor cells are accumulated in accessible body compartments [22-24].

The development of effective systems applied locally to cancer therapy must consider the heterogeneity between tumor and normal tissue. Parts of tumor tissue are frequently hypoxic, resulting in high glycolysis rates, required for energetic cell supply. Consequently, the production of lactic acid results in an acid microenvironment [25-27]. A broad range of $\mathrm{pH}$ values are reported for malignant tissues, however, variations are comprised, mostly, between 5.8 and $7.4[25,28,29]$.

Among all matrices used to delivery anticancer drugs directly to tumor site, hydrogels stand as suitable candidates [30-34]. Their high biocompatibility, reflected by their capacity to absorb large amounts of biological fluids, renders a similarity to natural extracellular matrix, mechanically and compositionally. Besides that, the tridimensional porous structure, features a distinctive drug delivery profile, which can be controlled by drug-matrix associations, drug diffusion though the network and system degradation [35]. A series of biocompatible polymeric materials have already been described for hydrogel development [30,33,36,37], among them, alginate polysaccharide has remarkable interest as biomaterial and tissue engineering [38,39].

Alginate polymer has a peculiar gelling property under physiological conditions, holding a good stability over a wide $\mathrm{pH}$ range, in addition to being a polyelectrolyte surrounded by negative charges, which offers the possibility of supramolecular association with positively charged BVZ molecule $[40,41]$.

Attempting to rescue the use of BVZ as anti-VEGF therapy in cancer and, inspired by biologic systems and tumor microenvironment characteristics, herein, we exploited calcium alginate hydrogels and the BVZ interaction to design anti-angiogenic delivery systems for localized therapy [26]. To achieve this goal, the influence of alginate polymer on bevacizumab thermal and conformational stability was firstly evaluated under physiological ( $\mathrm{pH} 7.4$ ) and tumor hypoxic microenvironmental conditions ( $\mathrm{pH} 5.8$ extreme reported value). The hydrogel was produced by mixing alginate solution with the anti-VEGF agent bevacizumab, followed by a subsequent crosslinking process within calcium chloride. Detailed characterization of the physicochemical properties was conducted. The anti-angiogenic and anti-neoplastic potential of the developed hydrogel_BVZ was assessed by the in vivo chicken chorioallantoic membrane (CAM) model. Our study provides a proof of concept that BVZ loaded calcium alginate hydrogel is effective as a release platform for the resumption of anti-VEGF local cancer therapy, in addition to promote an improved drug anti-angiogenic and anti-neoplastic activity independent on the $\mathrm{pH}$ encountered in the tumors.

\section{Experimental section}

\subsection{Materials}

Medium viscosity alginate sodium salt, derived from brown algae, was purchased from Sigma-Aldrich (United Kingdom). Polymer molecular weight was $107 \pm 3.42 \mathrm{kDa}$, as measured by Static light scattering. The polymer mannuronic/guluronic $(\mathrm{M} / \mathrm{G})$ ratio was 1.93 determined by ${ }^{1} \mathrm{H}$ NMR, according to Grasdalen $[42,43]$. Calcium Chloride $\left(\mathrm{CaCl}_{2}\right)$ was purchased from Vetec. Avastin ${ }^{\circledR}$ (Bevacizumab injection $25 \mathrm{mg} / \mathrm{mL}$, Roche Pharma Ltd., Switzerland) was purchased from Genentech. All other chemicals including sodium chloride, lactic acid, dibasic sodium phosphate, hydrochloric acid, sodium hydroxide were analytic reagent grades, purchased from Sigma-Aldrich (São Paulo, Brazil). Dulbecco's Modified Eagle Medium Gibco ${ }^{\circledR}$ and all materials used for cell supply were purchased from Invitrogen. Milli-Q grade water (Millipore ${ }^{\circledR}$ ) was used for hydrogel preparation.

\subsection{Methods}

\subsubsection{Effect of $\mathrm{pH}$ and polyanion alginate on bevacizumab} conformational and thermal stability

2.2.1.1. Circular dichroism (CD). Changes in secondary structure of bevacizumab were evaluated in the presence of alginate polymer using a Jasco J-815 spectropolarimeter coupled to a Peltier-type temperature control system PFD 425S. BZV CD spectra were measured in $0.1 \mathrm{~mm}$ quartz cuvette containing polymer/protein $(1: 9-$ 0.05/0.45 mg. $\mathrm{mL}^{-1}$ and 5:5 - 0.25/0.25 mg.mL ${ }^{-1}$ ) concentration in $50 \mathrm{mM}$ phosphate-acetate buffer ( $\mathrm{pH} 5.8$ or 7.4$)$ and compared with freshly prepared bevacizumab $\left(0.3 \mathrm{mg} \cdot \mathrm{mL}^{-1}\right)$. Blank solutions containing polymer at the same concentrations were measured to subtract polymer contributions from the resultant CD spectra. Spectra were collected at a $100 \mathrm{~nm} / \mathrm{min}$ scan rate with of $0.5 \mathrm{~nm}$ data pitch and normalized to mean residue molar ellipticity $([\theta])$. Protein secondary structure content was estimated using the CDNN Deconvolution program [44].

2.2.1.2. Fluorescence spectroscopy. Protein local tertiary structure and stability were analyzed by intrinsic fluorescence emission experiments using F-4500 Hitachi fluorescence spectrophotometer and $10 \times 2 \mathrm{~mm}$ path length quartz cuvettes. Samples, composed of $0.5 \mathrm{mg} . \mathrm{mL}^{-1}$ alginate/bevacizumab at three different polymer/protein ratios (1:9, 5:5 and 9:1) were excited at $280 \mathrm{~nm}$ and emission spectra were collected from 300 to $420 \mathrm{~nm}$. All measurements were performed in $50 \mathrm{mM}$ phosphate-acetate buffer ( $\mathrm{pH} 5.8$ or 7.4) and compared with freshly prepared bevacizumab $(0.3 \mathrm{mg}$. $\mathrm{mL}^{-1}$ ). A blank solution containing the same polymer concentration was used as reference. Intrinsic fluorescence emission data were analyzed using the maximum emission wavelength $\left(\lambda_{\max }\right)$ and the center of spectral mass $(<\lambda>)$, described by Eq. (1).

$\langle\lambda\rangle=\frac{\sum F i \lambda i}{\sum F i}$

Where $F i$ is the fluorescence intensity at each $\lambda i$ wavelength.

\subsubsection{Differential Scanning Microcalorimetry (Nano-DSC). DSC} measurements were made using a TA Instruments Nano-DSC. Thermal denaturation scans were conducted from 0 to $100^{\circ} \mathrm{C}$ at a rate of $1 \mathrm{C} . \mathrm{min}^{-1}$. Acquired data shows thermal profile of freshly prepared BVZ and BVZ against the presence of alginate polymer in phosphate-acetate buffer pH 5.8 and 7.4. The reference cell was filled with buffer solution and buffer solution containing alginate. Thermodynamic parameters related to protein unfolding were extracted from thermograms using Nano Analyze software. 
2.2.1.4. Preparation of BVZ loaded alginate hydrogel. Sodium alginate was first dispersed "overnight" $(27 \mathrm{mg} / \mathrm{mL}$ ) in purified water using magnetic stirring at room temperature. $\mathrm{pH}$ was adjusted by the use of hydrochloric acid ( $\mathrm{pH} 5.8$ ) and sodium hydroxide ( $\mathrm{pH} 7.4$ ) solutions. For hydrogel preparation, a co-injection system with alginate solution $(10 \mathrm{~mL})$ and the same amount of calcium chloride $(5 \mathrm{mg} /$ $\mathrm{mL}$ ) as crosslink agent was used [45]. The co-injection system was based in the homogeneous addition of the polymer and crosslinking solution, dropwise, under mechanical stirring. The $\mathrm{pH}$ was controlled, and a maximal $\mathrm{pH}$-deviation of \pm 0.1 was allowed. For systems containing BVZ protein (referred as hydrogel_BVZ), bevacizumab $(3 \mathrm{mg} / \mathrm{mL})$ was added before the crosslinking process in polymer solution. In order to complete the process, hydrogels were left under magnetic stirring for 30 min after preparation.

2.2.1.5. Zeta potential measurements. Samples were prepared as already mentioned and placed in a plastic cuvette. Zeta potential (ZP) of hydrogel at pH 7.4 and hydrogel_BVZ at pH 7.4 and 5.8 was determined by electrophoretic mobility using a Malvern Instruments Zetasizer Nano ZS (United Kingdom) to analyze the self-assembly process. Samples were diluted in ultra-purified water. All data were obtained using the HelmholtzSmoluchowski approximation.

2.2.1.6. Syringeability test. Syringeability expresses the force required for system injection at a given injection rate via a syringe attached to a needle of predetermined gauge and length [46]. The work required to extrude hydrogels produced with different concentrations of calcium chloride $(3 \mathrm{mg} / \mathrm{mL}$ and $5 \mathrm{mg} / \mathrm{mL}$ ), hydrogel_BVZ and commercial BVZ were determined using the TAXTplus Texture Analyzer (Stable Micro Systems ${ }^{\circledR}$ ) in compression mode, by measuring the area under the resultant force [47-49]. Briefly, hydrogels were carefully packed into identical $3 \mathrm{~mL}$ plastic syringes (BD Plastipak ${ }^{\mathrm{TM}}$ ) coupled to $0.70 \times 30 \mathrm{~mm}$ needle (BD Precision Glide $\left.{ }^{\mathrm{TM}}\right)$, avoiding the introduction of air bubbles, ensuring $30 \mathrm{~mm}$ of formulation. The syringe was then vertically placed under the probe, which was lowered up to the initial contact with the plunger. To determine the work done, the probe was lowered at constant speed $\left(2 \mathrm{~mm} . \mathrm{s}^{-1}\right.$ through a distance of $\left.30 \mathrm{~mm}\right)$. Increased work of syringeability was related to increased areas under the curves. All measurements were performed at $25^{\circ} \mathrm{C}$ and, at least in six replicates.

2.2.1.7. Hydrogel liquid uptake. Evaluation of hydrogel liquid uptake capacity was performed by using an Enslin device [50,51] at both 5.8 and $7.4 \mathrm{pH}$ values (phosphate-acetate buffer $50 \mathrm{Mm}$ ). For the assay, $3 \mathrm{mg} \pm 0.5$ of lyophilized hydrogel and hydrogel_BVZ samples were placed on the sintering filter. The volume of the media was measured with a graduated pipette, coupled to the system. Experiments were carried out in triplicate and results expressed as sorption volume (S\%) after 15, 30, 60, 120, 150 and $180 \mathrm{~min}$ according to Eq. (2).

$S \%=\frac{\mathrm{V}}{\mathrm{m}} \times 100$

where $\mathrm{S} \%$ is the percentage of sorption volume; $\mathrm{V}$ is volume $(\mathrm{mL})$ of media absorbed and $m$, initial mass of hydrogels.

2.2.1.8. Rheological behavior. Continuous flow and viscoelastic properties of hydrogel and hydrogel_BVZ ( $\mathrm{pH} 7.4)$ were analyzed on a TA Instruments ${ }^{\circledR}$ AR2000ex rheometer equipped with parallel-plate geometry of $40 \mathrm{~mm}$ diameter, angle $2^{\circ}$ and gap $61 \mu \mathrm{m}$. A total of $1.2 \mathrm{~mL}$ samples were carefully deposited onto the lower base and equilibrated for $5 \mathrm{~min}$ before starting the measurements. The flow test was performed using a controlled shear rate procedure in the range of $1-400 \mathrm{~s}^{-1}$ and back, each stage lasting $180 \mathrm{~s}$.

Oscillatory rheology measurements were fulfilled within the linear viscoelastic region, applying $0.01-100 \mathrm{~Hz}$ frequency sweep at a constant stress $(0.5 \mathrm{~Pa})$ to record storage modulus $\left(\mathrm{G}^{\prime}\right)$ and loss modulus $\left(\mathrm{G}^{\prime \prime}\right)$, which can provide useful information about the gel structure [51,52]. Exponent $n$ was obtained by fitting $\mathrm{G}^{\prime}$ as a function of frequency $(\omega)$ into the power law equation (Eq. (3)) [41,53], given by:

$G^{\prime}=S \cdot \omega^{n}$

where $G^{\prime}$ is the storage modulus; $S$ the gel strength; $\omega$ the oscillation frequency and $n$ is the viscoelastic exponent.

The temperature was maintained at $25 \pm 0.1{ }^{\circ} \mathrm{C}$ during all measurements. In order to mimic system behavior at the acidic tumor microenvironment, hydrogel and hydrogel_BVZ were additionally analyzed against the presence of lactic acid ( $\mathrm{pH}$ 5.8). All reported values are the average of triplicate determinations.

2.2.1.9. Scanning electron microscopy. Field emission scanning electron microscopy (FEG-SEM) was performed on hydrogel and hydrogel_BVZ to analyze gel porosity and morphology. Hydrogels were instantly frozen by using liquid nitrogen and lyophilized for $48 \mathrm{~h}$. A cross section of hydrogel sample was mounted with carbon tape and coated with gold. Samples were imaged using a JOEL-JSM7500 F coupled to Joel Pc-100 ver. 2.1.0.3. Software.

\subsection{Biological performance}

\subsubsection{Cells and cell culture}

A glioma cell line (U251) was used for these studies as a model of tumor cells, it was provided by Professor Joseph Costello, California University, Neurosurgery department, San Francisco. Authentication was performed at IdentiCell Laboratories (Department of Molecular Medicine at Aarhus University Hospital Skejby, Arhus, Denmark). The cell line was maintained in Dulbecco's Modified Eagle's Medium (DMEM $1 \times$, High Glucose; Gibco, Invitrogen) supplemented with $10 \%$ fetal bovine serum (Gibco, Invitrogen) and $1 \%$ penicillin/streptomycin solution (Gibco, Invitrogen) at $37^{\circ} \mathrm{C}$ and $5 \% \mathrm{CO}_{2}$.

\subsubsection{The chicken chorioallantoic membrane (CAM) assay}

The anti-angiogenic and anti-neoplastic activity was assessed as previously described, with slight modifications [8,54-56]. Briefly, fertilized chicken eggs $(n=90-120$, Pintobar, Portugal) were initially incubated horizontally at $37{ }^{\circ} \mathrm{C}$ with $70 \%$ humidity for a three-day period. Posteriorly, on the third day of development, in a laminar-flow hood, eggs were cleaned by using $70 \%$ ethanol solution and a window, diameter around $2 \mathrm{~cm}$, was made on the top of the egg shells by thoroughly removing shell fragments, enabling access to the CAM. The windows were then covered with invisible tape $(55 \times 30 \mathrm{~mm}$; BTK) to avoid egg dehydrating and incubated as initially [54-56]. On the ninth day of development, four experimental groups $(\mathrm{n}=10)$ were tested: DMEM (Dulbecco's modified eagle medium as negative control), hydrogel, hydrogel_BVZ and BVZ (Commercial anti-VEGF bevacizumab, Avastin, Genentech/ Roche, USA) as positive control. All experimental groups were treated at both 5.8 and $7.4 \mathrm{pH}$ values. Pictures of the CAM implants were taken over time in ovo by the use of a stereomicroscope (Olympus S2 $\times 16$ ) coupled to Cell B basic imaging software (Olympus) to document vascular changes [57].

On the 17th day of development, samples of the CAM tissue were excised using suture scissors, fixed with paraformaldehyde solution $3.7 \%(v / v)$, processed, sectioned and stained. For quantification purposes, the magnification of the stereomicroscope image 
was kept constant $(7 \times)$ and pictures taken ex ovo were processed as $300 \times 300$ pixels around the hydrogel area. Blood vessels were counted by the use of ImageJ $1.48 \mathrm{v}$ Software. Counts for each egg were performed by two independent observers to minimize failure and average values were used as a result.

To further analyze the anti-neoplastic activity, the eggs were initially treated as previously described. On day 9 of development, U251 cells $\left(2 \times 10^{6}\right.$ cells in $20 \mu$ L DMEM medium) were implanted into the CAM using a matrigel support. After 3 days, tumor area and perimeter was measured in ovo using the Cell B software (Olympus) [8]. Eggs were than separated into two experimental groups: hydrogel group (received $20 \mu \mathrm{L}$ of hydrogel_BVZ pH 5.8) and control group (received no treatment). On day 17 of development, chorioallantoic membranes with tumors were excised, photographed for blood vessel quantification purposes and transferred to histological cassettes embedded in paraffin for immunohistochemistry analysis. Three independent CAM assays were performed.

\subsubsection{Immunohistochemistry analysis}

Representative $3 \mu \mathrm{m}$-thick of CAM sections containing microtumors were used to immunohistochemical analysis, according to the streptavidin-biotin peroxidase complex system (UltraVision Large Volume Detection System anti-Polyvalent, HRP; LabVision Corporation) [54,55].

Briefly, deparaffinised slides were rehydrated and submitted to heat-induced antigen retrieval, $20 \mathrm{~min}$ at $98^{\circ} \mathrm{C}$ using $10 \mathrm{mM}$ citrate buffer ( $\mathrm{pH}$ 6.0; Merck). After endogenous peroxidase inactivation ( $3 \% \mathrm{v} / \mathrm{v}$ hydrogen peroxide solution) and washing in phosphate buffered saline (PBS), CAM sections were incubated with the primary protein blocking solution followed by the primary antibody raised against lectin (1:300, 2 hours- Vector Laboratories) at room temperature. To complete the assay, sections were sequentially washed with PBS and incubated with secondary antibody, streptavidin-biotin peroxidase complex followed by 3diaminobenzidine (DAB, Thermo Scientific), $10 \mathrm{~min}$. Sections were than counterstained with Gill-2 hematoxylin (Merck). Images of the histological sections were acquired at $100 \times$ magnification using an Olympus $\mathrm{B} \times 16$ microscope connected to CellP image processing software (Olympus).

\subsubsection{Statistical analysis}

All experiments were performed in a blind manner, at least in triplicate. For comparison of two independent groups at a certain time point, the pair wise Student's $t$-test was used for statistical evaluation. In case of simultaneous comparison of all groups oneway analysis of variance (ANOVA) with Tukey's multiple comparison tests was used, considering significant values to be 0.05 $(\mathrm{p}<0.05)$.

\section{Results and discussion}

The success of current anti-VEGF therapy applying bevacizumab, still presents some concerns, especially due to its hydrophilicity, high molecular weight and low stability in biologic fluids, which might be overcome by developing an efficient carrier system for localized therapy. The purpose of the present study was to develop a delivery system able to be applied by intratumoral injections, allowing high drug concentrations at the tumor site, improve drug stability and promote drug controlled release over time. Alginate hydrogels were chosen for this propose since they represent a biocompatible polyanion matrix able to interact with the monoclonal antibody bevacizumab (isoelectric point \pm 8.3 ), especially at $\mathrm{pH}$ values lower than physiologic 7.4 [41], most likely, without altering drug structure, since their preparation does not require the use of extreme temperatures or organic solvents.

\subsection{Effect of $p H$ and polyanion alginate on bevacizumab conformational and thermal stability}

The maintenance of protein biopharmaceutical conformational stability is essential to assure biological activities [58]. To address this issue, we have employed circular dichroism and intrinsic fluorescence spectroscopy measurements to monitor secondary and tertiary BVZ structure, respectively. Fig. 1A shows CD spectra of BVZ, normalized for MRE, at pH 5.8 and 7.4 compared to BVZ in the presence of different polymer proportions, for both $\mathrm{pH}$ values. For all tested conditions, BVZ CD spectra exhibited structural elements related to $\beta$-sheet proteins, with a negative band between 210 and $220 \mathrm{~nm}$ [59]. The mixture of alginate polymer and BVZ in the ratio 1:9 and 5:5 led to a small reduction of the CD signal without spectra profile changes at both tested pH values. Furthermore, structure estimation did not indicate significant changes in the secondary structure content of BVZ due to the presence of alginate (see Table 1 ).

Fluorescence emission is an average of all contributions of tryptophan residues present in the BVZ structure, which can undergo slight changes according to the environment polarity caused by $\mathrm{pH}$ modification [60]. Reinforcing the aforementioned results, the BVZ structural stability in mixtures with alginate polymer (in 1:9, 5:5 and 9:1 ratios) was analyzed using intrinsic fluorescence. Fig.1B shows the normalized BVZ fluorescence spectra at both $\mathrm{pH}$ values, indicating no significant changes in BVZ tertiary structure. Furthermore, analysis of $\lambda_{\max }$ and $\langle\lambda\rangle$ did not demonstrate differences between all samples.

DSC measurements provide heat changes during controlled temperature modifications and might indicate the occurrence of thermal denaturing events and disruptions of interactions that maintain the tridimensional structure [61]. The DSC profiles of $\mathrm{BVZ}$ and BVZ in the presence of alginate polymer, for both $\mathrm{pH}$ values, were similar to temperature-induced unfolding of a typical humanized monoclonal antibody. Two transitions were observed. The first event occurs around $70{ }^{\circ} \mathrm{C}$ and is related to Fab (fragment antigen binding) and one domain in Fc (fragment crystallizable) unfolding fragment, while the second event corresponds to melting of the Fc fragment, which occurs around $80^{\circ} \mathrm{C}$, in agreement with the previously reported BVZ profile [62]. Table 2 summarizes the results of DSC measurements of BVZ and BVZ in the presence of alginate for $\mathrm{pH} 5.8$ and 7.4 .

Values of melting temperature $\left(T_{\mathrm{m}}\right)$ and enthalpy appear to be higher when BVZ is in the presence of the polymer. Although there were no significant differences in the $T_{\mathrm{m}}$ between all samples, there was a substantial increase in enthalpy when measures were conducted in the presence of alginate. These data indicate that the polyanion might improve protein thermal stability in both $\mathrm{pH}$ values by increasing the energy required for protein denaturation. Furthermore, the presence of alginate may cause restricted protein mobility, harming the unfolding process. The thermal stabilizing nature action of polymers against protein has been mentioned in several studies $[63,64]$. These hypotheses are supported by DC and fluorescence analysis since the presence of the polymer did not affect the secondary and tertiary protein structure. Altogether, these results indicate that BVZ has structural and thermal stability in the presence of the alginate polyanion for both tested conditions.

\subsection{Hydrogel preparation through electrostatic forces}

Alginate, a natural polysaccharide derived from brown algae, is composed by $\beta$-D-mannuronic acid residues (M blocks) and $\alpha$-L- 

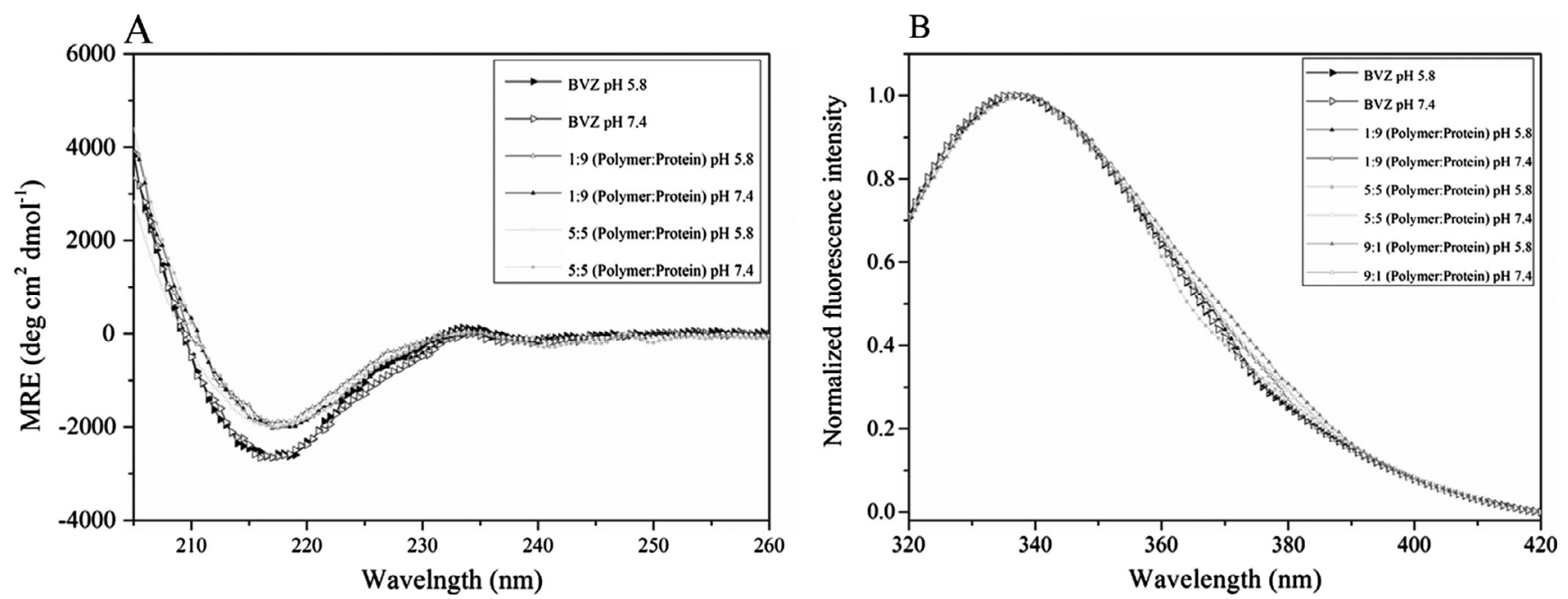

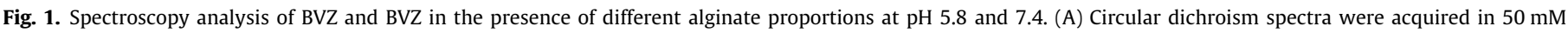

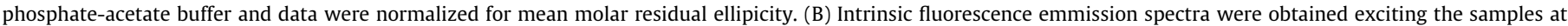
$280 \mathrm{~nm}$ and collecting fluorescence emmission from $300 \mathrm{~nm}$ to $420 \mathrm{~nm}$; data were normalized.

Table 1

Summary of spectroscopy results. Effect of pH value and polyanion alginate on BVZ conformational structure.

\begin{tabular}{|c|c|c|c|c|c|c|c|c|c|}
\hline \multirow[t]{3}{*}{ Technique } & \multirow[t]{3}{*}{ Property } & \multirow{2}{*}{\multicolumn{2}{|c|}{$\mathrm{BVZ}^{\mathrm{a}}$}} & \multicolumn{6}{|c|}{ Polymer:Protein } \\
\hline & & & & \multicolumn{2}{|l|}{$1: 9$} & \multicolumn{2}{|l|}{$5: 5$} & \multicolumn{2}{|l|}{$9: 1$} \\
\hline & & pH 5.8 & pH 7.4 & pH 5.8 & $\mathrm{pH} 7.4$ & pH 5.8 & $\mathrm{pH} 7.4$ & pH 5.8 & $\mathrm{pH} 7.4$ \\
\hline \multirow[t]{4}{*}{$\mathrm{CD}^{\mathrm{b}}$} & $\alpha$-helix & 5 & 5 & 4 & 5 & 5 & 4 & \multirow{4}{*}{\multicolumn{2}{|c|}{$\mathrm{n} / \mathrm{d}$}} \\
\hline & $\beta$-sheet & 47 & 46 & 49 & 48 & 48 & 49 & & \\
\hline & $\beta$-turn & 17 & 17 & 17 & 17 & 17 & 16 & & \\
\hline & Random coil & 35 & 35 & 35 & 35 & 35 & 35 & & \\
\hline \multirow[t]{2}{*}{ Fluorescence $^{c}$} & $\lambda_{\text {máx }}(\mathrm{nm})$ & 337 & 337 & 337 & 338 & 338 & 336 & 337 & 337 \\
\hline & $<\lambda>(\mathrm{nm})$ & 350.2 & 350.2 & 350.4 & 350.5 & 350.5 & 350.5 & 351.5 & 350.9 \\
\hline
\end{tabular}

${ }^{\text {a }}$ Freshly prepared bevacizumab $0.3 \mathrm{mg} \cdot \mathrm{mL}^{-1}$.

b Secondary structure extracted by deconvolution of experimental CD spectra using CDNN deconvolution program. Results represent average of three determinations (\%). Standard deviation was lower than $5 \%$

${ }^{c}$ Wavelength of maximum emission $\left(\lambda_{\max }\right)$ and mass spectral center $(<\lambda>$ ) extracted from intrinsic fluorescence. Results represent average of three determinations. Standard deviation was lower than $2.0 \mathrm{~nm}$.

Table 2

Experimental values for melting temperatures and enthalpies of BVZ and BVZ in the presence of alginate polymer at pH 5.8 and 7.4.

\begin{tabular}{|c|c|c|c|c|c|}
\hline \multirow[t]{2}{*}{ Sample } & \multirow[t]{2}{*}{$\mathrm{pH}$} & \multicolumn{2}{|c|}{ First transition } & \multicolumn{2}{|c|}{ Second transition } \\
\hline & & $T_{\mathrm{m}}\left({ }^{\circ} \mathrm{C}\right)^{*}$ & Enthalpy" (Kcal/mol) & $T_{\mathrm{m}}\left({ }^{\circ} \mathrm{C}\right)^{*}$ & Enthalpy ${ }^{*}(\mathrm{Kcal} / \mathrm{mol})$ \\
\hline BVZ & 5.8 & 65.5 & 399.9 & 84 & 25.9 \\
\hline $\mathrm{BVZ}+$ Alginate & & 72.7 & 547.8 & 84.2 & 38.7 \\
\hline BVZ & 7.4 & 69.6 & 334.9 & 82.9 & 27.2 \\
\hline $\mathrm{BVZ}+$ Alginate & & 72.2 & 546.9 & 84.2 & 40.04 \\
\hline
\end{tabular}

* Data show an average of three measures. Standard deviations were less than $3^{\circ} \mathrm{C}$ and $10 \mathrm{Kcal} / \mathrm{mol}$ for temperature and enthalpy.

guluronic acid residues ( $\mathrm{G}$ blocks) covalently linked in different blocks, arranged along the polymer chain. In the presence of divalent ions, such as calcium, a crosslink between carboxylic groups present on $\mathrm{G}$ blocks can provide the formation of a tridimensional network [65-67]. The chemical crosslinking process used to prepare hydrogels comprises a soluble salt, calcium chloride. External gelation was chosen for hydrogel production once local variations as temperature and $\mathrm{pH}$ are expected at the heterogeneous tumor microenvironment. The control of stoichiometry between the polymer and crosslinking agent, in addition to the use of co-injection system between alginate and calcium chloride solutions, ensured good homogeneity and stability of the produced polymeric network.
To evaluate the interaction between the oppositely charged BVZ and alginate into the hydrogel system we have used zeta potential measurements. ZP average values found for produced hydrogels assumed values around $-50.4 \pm 2.7 \mathrm{mV}$ at physiologic $\mathrm{pH}$ (7.4). Introduction of $\mathrm{BVZ}$ protein promoted a decreased in $\mathrm{ZP}$ $(-44.3 \pm 3.2 \mathrm{mV})$, reinforcing an event of supramolecular association between the anionic matrix and the positively charged protein. Furthermore, the ZP value of hydrogel_BVZ at pH 5.8 was $-33.2 \pm 1.11 \mathrm{mV}$. These results were significantly different $(\mathrm{p}<0.05)$ and highlight a stronger and enhanced interaction between the protein and polyanion at $\mathrm{pH}$ 5.8. At this condition, although the alginate hydrogel charge density does not appear to change significantly between $\mathrm{pH} 7.4$ and 5.8, according to their pKa value, the $\mathrm{pH}$ drop promotes $\mathrm{BVZ}$ protonation and exhibition 
of a larger number of positive charges along its surface. The highest exposure of BVZ positive charges at $\mathrm{pH} 5.8$ increases the proteinpolyanion association, promoting a reduction in the ZP value. Schweizer and co-workers have previously explored electrostatic interactions between calcium alginate hydrogel and a monoclonal antibody $(\mathrm{mAb})$ for its sustained release. The supramolecular established interactions, demonstrated a $\mathrm{pH}$ dependence on the release rates and stronger alginate $-\mathrm{mAb}$ association under acidic conditions, where the mAb carries a large number of positive charges [41].

In summary, ZP data shows that BVZ loaded alginate hydrogel self-assembly by electrostatic forces at both studied $\mathrm{pH}$ values. However, the data also suggest stronger alginate-BVZ interactions at $\mathrm{pH}$ 5.8.

\subsection{Hydrogel mechanical behavior}

To enable an intratumoral application, the developed formulations must be able to be delivered by a syringe through a needle. As an injectable system, the formation of aggregates cannot be allowed during the injection process, to avoid needle clogging. Results of hydrogels, hydrogel_BVZ and commercial BVZ syringeability are shown in Table 3 . The observed syringeability values were adequate for slow and continuous injections, with no evidence for aggregate formation, ranging from 9 to 29 N.mm, within the overall limit for manual injection [49]. Comparing the use of two different crosslinking agent concentrations, higher concentration promotes a significant increase in the work required for hydrogel ejection. Moreover, addition of BVZ also promoted a higher seringeability value. Meanwhile, the absence of BVZ on hydrogel formulation results in systems slightly more prone to flow. A low syringeability value was expected for commercial BVZ, which comprises an injectable solution for intravenous administration. Values of work required for system seringeability between 10 and $30 \mathrm{~N}$ were previously reported and classified as injectable and suitable for local administration [68].

Syringeability results can predict a shear thinning behavior of calcium alginate hydrogels. A decreased viscosity might be observed due the increased shear rates. This condition leads to a temporary network destruction against molecular alignment in the flow direction. Therefore, the applied force promotes a reversible disruption or disorganization of supramolecular entities, allowing flowability $[49,69]$.

Rheological studies were designed to provide a detailed characterization of hydrogel and hydrogel_BVZ flow behavior and its mechanical structure. Representative plots from flow behavior are displayed in Fig.2A. A typical non-Newtonian, shear thinning behavior, was observed for all samples regardless of drug load or $\mathrm{pH}$ value. The exhibited flow behavior, where decreased resistance to flow is related to increased shear rates, is commonly described for polymeric cross-linked alginate systems [70,71] and might be favorable for the proposed application.

The absence of bevacizumab in the hydrogel system results in an overlapping hydrogel profile for both 5.8 and $7.4 \mathrm{pH}$ values.
Moreover, addition of BVZ did not change the overall shape of the flow curve, but resulted in an increase in the stress required to generate an expressive deformation. These alterations might occur by the establishment of supramolecular interactions, which reduces chain mobility. However, it was expected that such behavior would have a stronger mark at acidic environment. Interestingly, hydrogel recovery did not occur immediately after shear removal, since hysteresis area was remarkable for all rheograms. When a shear stress is applied, the hydrogel network suffers partial damage. If the structure rebuilds within a short period of time, the structure experiences a shear thinning; otherwise, if restructuring takes a long time, rheopexy is announced. Undergoing shear stress, hydrogel_BVZ achieves structural reorganization connected to increased viscosity. This profile might ensure adequate flow during administration, followed by a tendency to thicken when stress is removed. Such behavior indicates a promising matrix for injectable drug delivery, performing a depot system following administration [72].

Further rheological analysis was performed at the linear viscoelastic region, where sample can elastically strain and return to its original state when straining is removed. A frequency sweep $(0.01 \mathrm{a} 100 \mathrm{~Hz})$ at constant stress $(0.5 \mathrm{~Pa})$ was performed to obtain hydrogel and hydrogel_BVZ mechanical spectra. The variation of $\mathrm{G}^{\prime}$ and G" values as a function of frequency is shown in Fig. 2B. As expected, all mechanical spectra revealed higher $G^{\prime}$ than $G^{\prime \prime}$, confirming an elastic behavior predominance of hydrogels. Furthermore, storage and loss modulus exhibited a slight frequency dependence. Increased $\mathrm{G}^{\prime}$ values were verified at lower $\mathrm{pH}$ conditions. Under these conditions, alginate $\mathrm{COO}-$ groups are protonated, enhancing $\mathrm{H}$-bonding and intermolecular cross-linking in the hydrogel network leading a higher $G^{\prime}$ values [73]. Rheological parameters of the hydrogel tended to be higher than hydrogel_BVZ. These results showed that addition of BVZ displayed internal network weakness what might be attributed to the drug plasticizer effect.

The use of power law model, $G^{\prime}=S . \omega^{n}$, where $S$ is the gel strength, $\omega$ is the angular frequency and $n$ the viscoelastic exponent, provides parameters that represent hydrogel's structure and strength. When hydrogel system exhibits a high crosslink density, the structure is considered strong and $S$ values are high. Moreover, $n$ value trends to decrease $[53,74]$. Thus, the evaluation of modified $S$ and $n$ values may enhance the occurrence of structural changes. S and $n$ values for hydrogel and hydrogel_BVZ at pH 5.8 and 7.4 are listed in Table 4. A significant difference in $S$ values was observed when the $\mathrm{pH}$ changes from 7.4 to 5.8. These findings might indicate an adoption of differential structure with higher rigidity due to the acidic environment.

Oscillatory studies showed that the drop in $\mathrm{pH}$ might lead to systems with higher structural organization once in the presence of lactic acid ( $\mathrm{pH}$ 5.8); a significant increase in $\mathrm{G}^{\prime}$ e $\mathrm{G}^{\prime \prime}$ values (Fig. 2B) was verified in addition to higher $\mathrm{S}$ values (Table 4). Increased elasticity at acidic environment occurs due to accentuated positively charged protein availability to ensure supramolecular interactions with alginate matrix [41]. Thus, hydrogel_BVZ

Table 3

Values of work required to expel each formulation from a syringe through a needle.

\begin{tabular}{|c|c|c|c|c|}
\hline \multirow[t]{2}{*}{ Formulations } & \multicolumn{3}{|c|}{ Concentration $(\mathrm{mg} / \mathrm{mL})$} & \multirow[t]{2}{*}{ Work (N.mm) } \\
\hline & Polymer & $\mathrm{CaCl}_{2}$ & Bevacizumab & \\
\hline Hydrogel_5 & 27 & 5 & - & $24 \pm 2.1$ \\
\hline Hydrogel_3 & 27 & 3 & - & $21 \pm 0.8$ \\
\hline Hydrogel_BVZ & 27 & 5 & 3 & $29 \pm 1.1$ \\
\hline Bevacizumab $^{\mathrm{b}}$ & - & - & 25 & $9 \pm 0.3$ \\
\hline
\end{tabular}

\footnotetext{
a Values represents the mean ( \pm standard deviation) of at least in six replicates at $25^{\circ} \mathrm{C}$.

b Commercial BVZ (Avastin ${ }^{\circledR} 25 \mathrm{mg} / \mathrm{mL}$ ).
} 

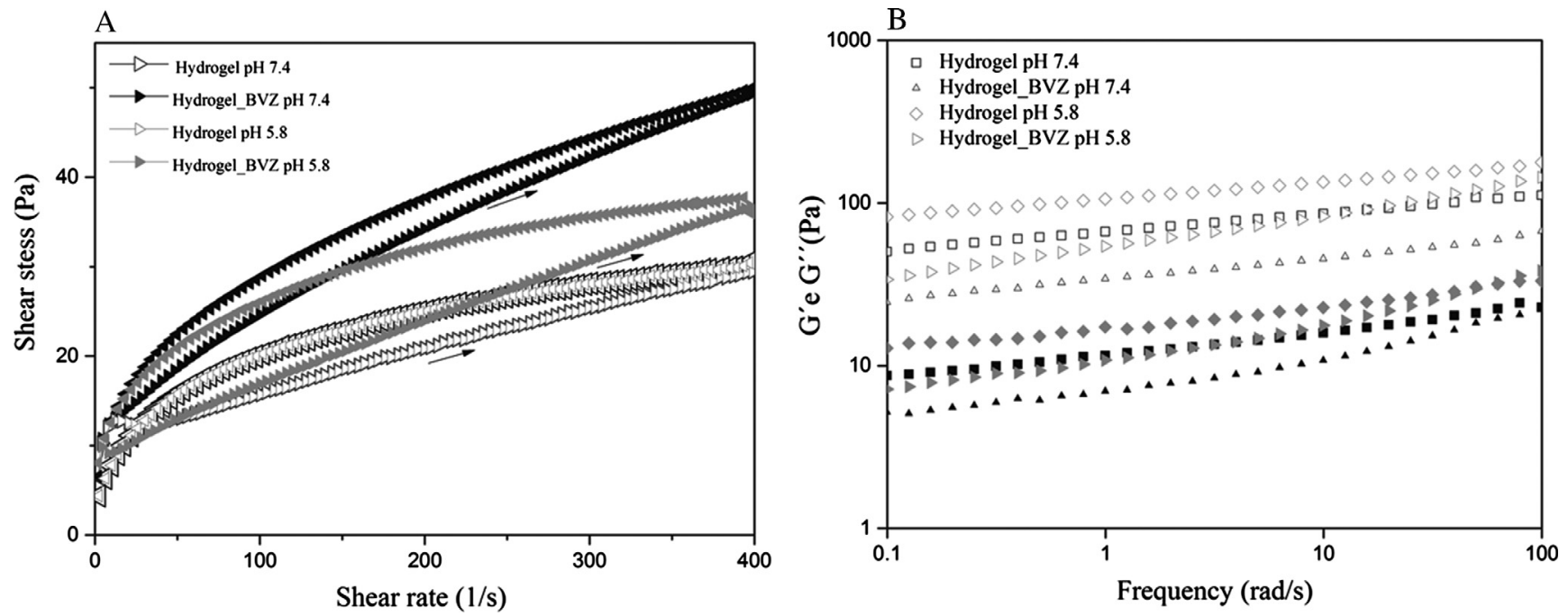

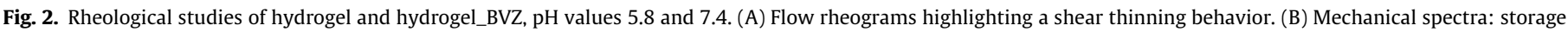

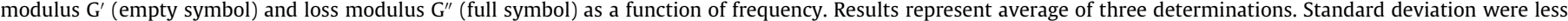
than $10 \%$ and have been omitted for clarity. Data were collected at $25 \pm 0.5{ }^{\circ} \mathrm{C}$.

Table 4

Viscoelastic exponent $(n)$ and gel strength (S) of hydrogel and hydrogel_BVZ at pH 7.4 and 5.8 .

\begin{tabular}{lll}
\hline Sample & $n^{*}$ & $\mathrm{~S}^{*}$ \\
\hline Hydrogel 7.4 & $0.12 \pm 0.01$ & $66.20 \pm 5.1$ \\
Hydrogel_BVZ 7.4 & $0.13 \pm 0.08$ & $34.01 \pm 2.4$ \\
Hydrogel 5.8 & $0.11 \pm 0.02$ & $110.81 \pm 3.1$ \\
Hydrogel_BVZ 5.8 & $0.21 \pm 0.03$ & $53 \pm 2.0$ \\
\hline
\end{tabular}

Value represents the mean $( \pm S D)$ of three replicates.

may adopt a different structural organization according to $\mathrm{pH}$ what might provide a differential BVZ release profile at the acidic tumor microenvironment where the system should be applied as local therapy.

\subsection{Hydrogel liquid uptake properties}

Polymeric matrices have received considerable attention over the past few years to develop improved drug delivery systems for protein drugs. From these systems, release of active drugs is dependent of drug diffusion through hydrogel matrix channels and pores, disruption of supramolecular interactions established between the matrix and drug and, subsequently, linked to polymer degradation [4]. Once these processes are directly related to liquid diffusion into the polymer network, the swelling behavior of the polymeric systems is an important property to be investigated and might promote a notable influence on drug-controlled release over time [75]. However, it is well established that the crosslinking process can promote immobilization of polymer chains, and consequently, reduction of the swelling ability [76]. The sorption profiles (S\%) of hydrogel and hydrogel_BVZ in phosphate-acetate buffer at pH 5.8 and 7.4, along three hours, are shown in Fig. 3.

Results revealed that hydrogel and hydrogel_BVZ exhibited high liquid uptake ability for both $\mathrm{pH} 5.8$ and 7.4. Moreover, these systems appear to present $\mathrm{pH}$ sensitive liquid uptake behavior once after $2.5 \mathrm{~h}$, a significant differences in the sorption volume ( $p>0.05$ ) between hydrogel at pH 5.8 and 7.4 was observed. A decreased uptake capacity at $\mathrm{pH} 5.8$ in anionic polymer hydrogels is related to hydrogen bound formation between the $-\mathrm{COOH}$ and $\mathrm{OH}$ groups [77]. Liquid uptake ability was reduced by the presence of BVZ (see hydrogel_BVZ). This reduction might be attributed to

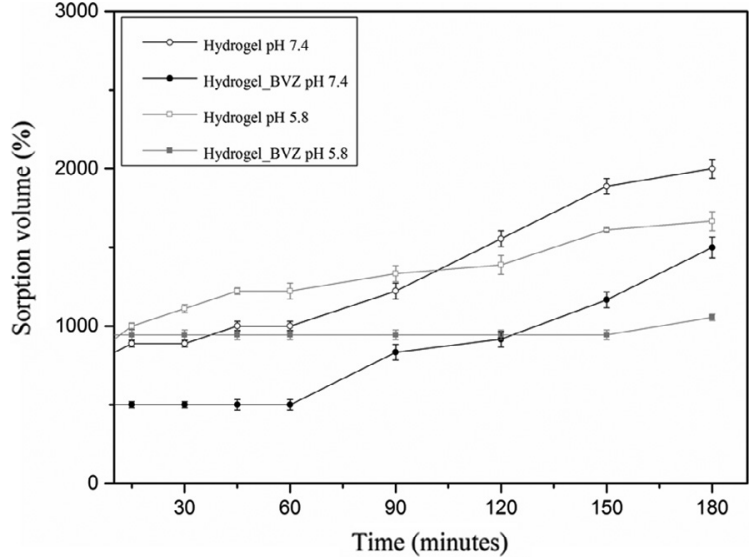

Fig. 3. Sorption profile (S\%) of hydrogel and hydrogel_BVZ in phosphate-acetate buffer $\mathrm{pH} 5.8$ and 7.4. Swelling behavior during three hours of monitoring. Results represents average of three determinations. Statistical significance between experimental groups were found after $2.5 \mathrm{~h}(\mathrm{p}>0.05)$.

the electrostatic interactions between the protein and anionic matrix, resulting in decreased charge density and repulsive forces into the network and, consequently, an approximation between the chains, obstructing the liquid absorption process. These results are in agreement with the zeta potential measurements, which have emphasized stronger interactions at lower $\mathrm{pH}$ values.

Due to the expected $\mathrm{pH}$ decrease in tumor microenvironment, these results might evidence important features acquired by the hydrogel system according to $\mathrm{pH}$ changes.

\subsection{Hydrogel surface morphology}

Surface morphology of hydrogel and hydrogel_BVZ was observed by SEM studies and the results are shown in Fig. 4. SEM photographs of hydrogels $(\times 300)$ revealed a rough surface highly interconnected by calcium ion cross-linked, yielding the formation of irregular pores with variable size, ranging from $100 \mathrm{~nm}$ to $100 \mu \mathrm{m}$, which may provide important features to this system. As a general aspect, calcium alginate hydrogels showed a squamous sheet on the surface, similar to those previously described 


\section{Hydrogel}

A

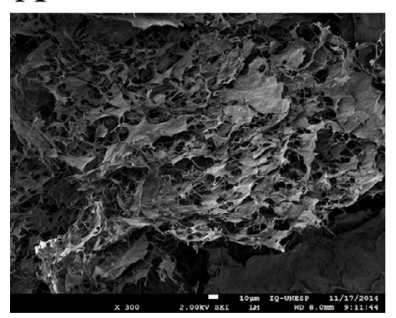

$\mathrm{B}$

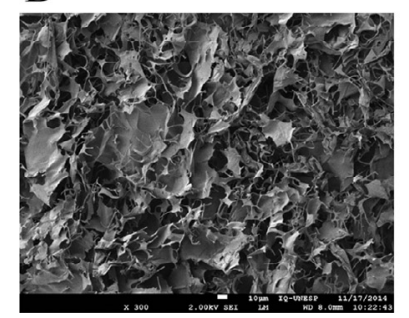

$\mathrm{C}$

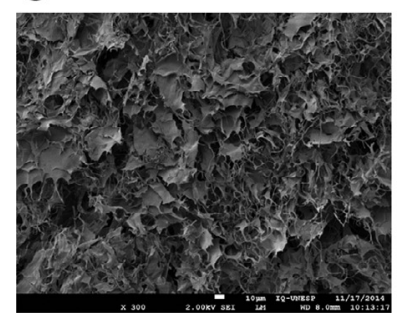

Hydrogel BVZ

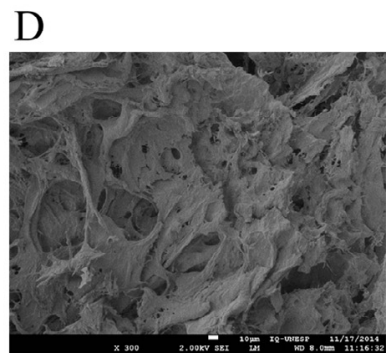

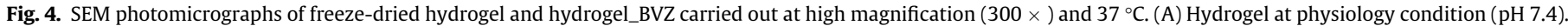
(B) Hydrogel at acidic environment (pH 5.8). (C) Hydrogel_BVZ at physiological condition (pH 7.4). (D) Hydrogel_BVZ at acidic environment (pH 5.8).

$[71,78]$. Photomicrographs of hydrogel (Fig. 4A and B) did not present any alteration on surface morphology due to $\mathrm{pH}$ modifications. However, the analysis of Fig. $4 \mathrm{C}$ and D demonstrate that hydrogel_BVZ originating a less squamous aspect at acidic environment, with a notable decrease in pore density. This observation can indicate that the association between protein-polyanion, at this condition, promotes a network reorganization, which adopts a different structure, corroborating all the data described above. The developed hydrogel_BVZ systems behave as supramolecular entities responsive to external stimuli as $\mathrm{pH}$ drop verified in the tumor microregion. The question is, therefore, the evaluation of system performance on tumoral environment.

\subsection{Investigation of the anti-angiogenic activity by chick embryo chorioallantoic membrane assay}

The purpose of use drug delivery systems to optimize the therapeutic effect in pathological processes such as cancer is promising; however, the understanding of system behavior towards biological environments is extremely important [79].

The increasing interest of the chick embryo as a model in biological and pharmaceutical research is based on the fact that the CAM offers an advantage to be a simple model, feasible for numerous samples in addition to its reliability $[57,80]$. The potential use of the CAM to study in vivo new vessel formation or their inhibition has been outlined by a series of publications, mainly, due to its dense capillary network [54,81-84]. Furthermore, this model is also noteworthy for the evaluation of drug delivery system (DDS) performance [85].

The ability of calcium alginate hydrogels to release antiangiogenic factors was evaluated by the CAM assay. Different samples ( $\mathrm{pH} 7.4$ and 5.8) were applied on the CAM on day 9 of embryonic development $[86,87]$. Stereomicroscopy images from DMEM, hydrogel, hydrogel_BVZ and BVZ groups ( $\mathrm{pH} 7.4$ and 5.8) acquired in ovo, after 3 days of treatment, are shown in Fig. 5A. It is possible to observe that the DMEM group has a typical vasculature regardless of the pH values. However, the hydrogel_BVZ group, after three days of treatment, exhibited collapsed blood vessels around the area where the systems were implanted (Fig. 5A). These results were also observed, although to a lesser degree, when BVZ was applied (Fig. 5A).

Although collapsed blood vessels can be found upon BVZ treatment, the dimension of its anti-angiogenic activity was less remarkable comparing to BVZ loaded hydrogel activity (Fig. 5A). Fewer blood vessels could be seen in the hydrogel_BVZ group, whereas the group treated with BVZ continued to show a dense capillary network. It can also be observed that the peripheral vessels grew centrifugally, avoiding the hydrogel_BVZ area, with an overall decrease in vascular density (Fig. 5A).
Macroscopic evaluation of anti-angiogenic response was carried out semi-quantitatively using ex ovo processed images after 7 days of applied treatment (Fig. 5B). Vessel counting disclose significant differences, converging between experimental groups. As expected, our negative control (DMEM) exhibited normal blood vessel growth and the number of vessels was higher than all other experimental groups, especially at $\mathrm{pH}$ 7.4. It can also be noticed that although blood vessels were able to proliferate in the presence of hydrogels, the average score of replicates showed that hydrogels by themselves, appear to promote reduction in blood vessel formation. The developed hydrogel provided modifications in the vessel grow pattern in addition to might act as an adsorbent of important key factors involved in vessel formation, a property strongly related to their sorption capacity. However, no difference between hydrogel and BVZ group was found at $\mathrm{pH}$ 5.8. Although BVZ applied to the CAM has resulted on the visualization of collapsed blood vessels, blood vessels seem to recover after a few days.

Our greatest promise is based on the fact that hydrogel_BVZ could promote further reduction in vascular density compared to BVZ alone (commercial anti-VEGF drug), results demonstrated at both $\mathrm{pH}$ values. These data, together with physicochemical characterization, complies with the hypothesis that our hydrogels might promote improvements on drug stability and activity. Despite both $\mathrm{pH}$ values exhibiting the same profile, statistically, it was not possible to correlate system activity and $\mathrm{pH}$ by using the CAM assay. These, jointly with other published data, leads us to believe that the CAM model, displaying a physiological $\mathrm{pH}$, might have worked as a buffer $[80,85,88,89]$.

The observation of groups treated with hydrogel_BVZ has further shown that the vascular apparatus becomes less dense over time (Fig. 6). This fact can indicated that developed hydrogel might promote BVZ controlled release over time. Besides reducing costs, extended half-life by slowing the release of antibody drugs can improve treatment effectiveness [18]. It has been demonstrated that BVZ can be released from polymeric systems over an extended period. Andrew and co-workers showed nanostructured mesoporous silica films, anionic materials similar to alginate hydrogels, which could interact with bevacizumab by supramolecular interactions, promoting sustained release of BVZ over a period of $>30$ days when it was applied on simulated eye vitreous [2]. Poly(DL-lactide-co-glycolide), known as PLGA nanoparticles, could release BVZ in a sustained fashion for over 90 days [19]. A developed thermosensitive biodegradable and biocompatible hydrogel produced by poly(2-ethyl-2-oxazoline)-b-poly( $\varepsilon$-caprolactone)-bpoly(2-ethyl-2-oxazoline) (PEOz-PCL-PEOz) was able to release BVZ at a constant rate of $40 \mu \mathrm{g} /$ day for 11 days without burst effect on its initial state [18].

These results highlighted that alginate hydrogel might promote drug-sustained release over time and displays improved anti- 
A

pH 7.4
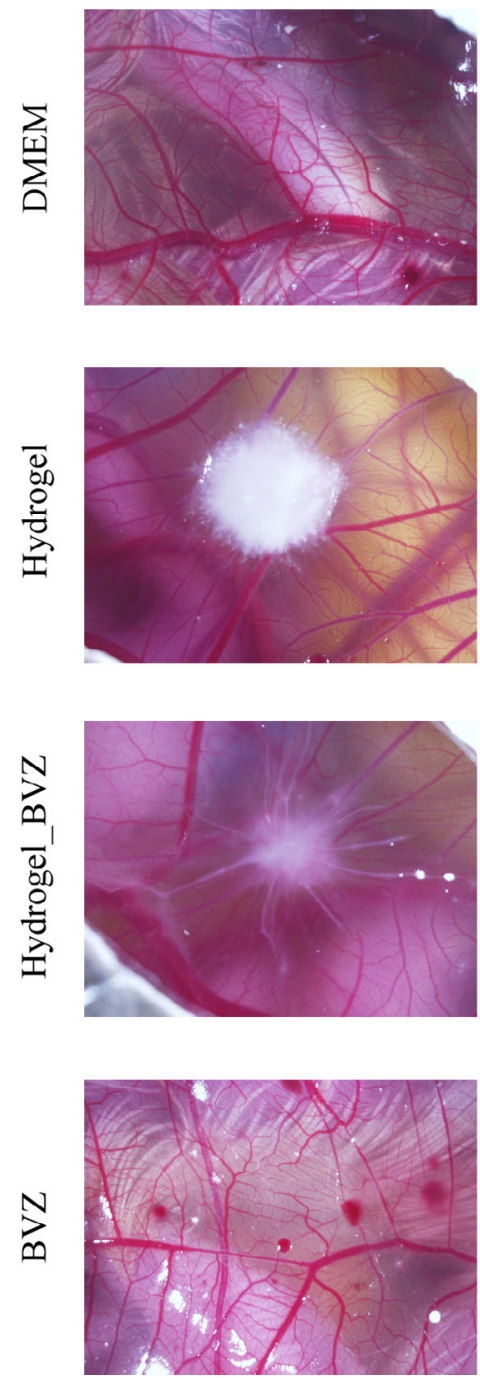

pH 5.8
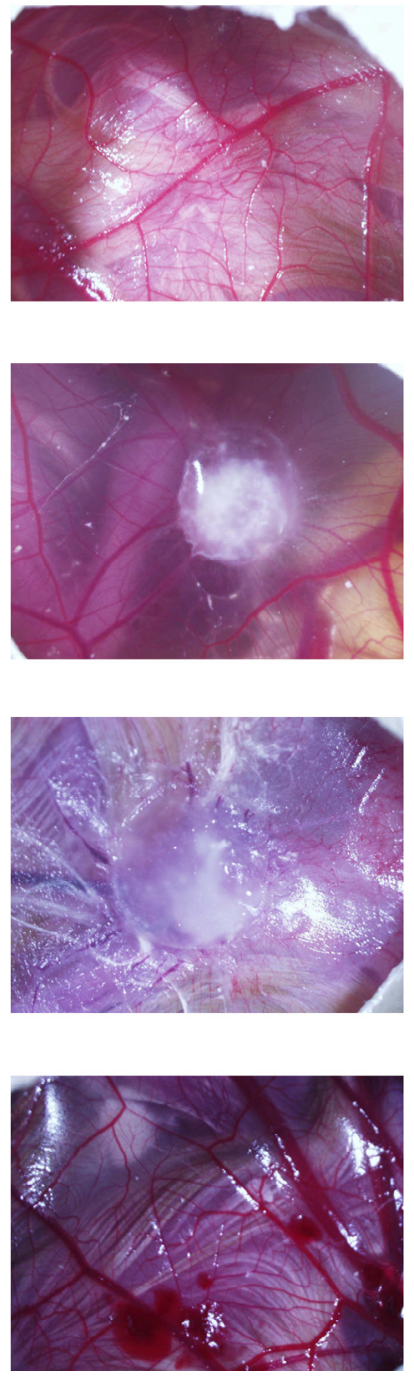

B
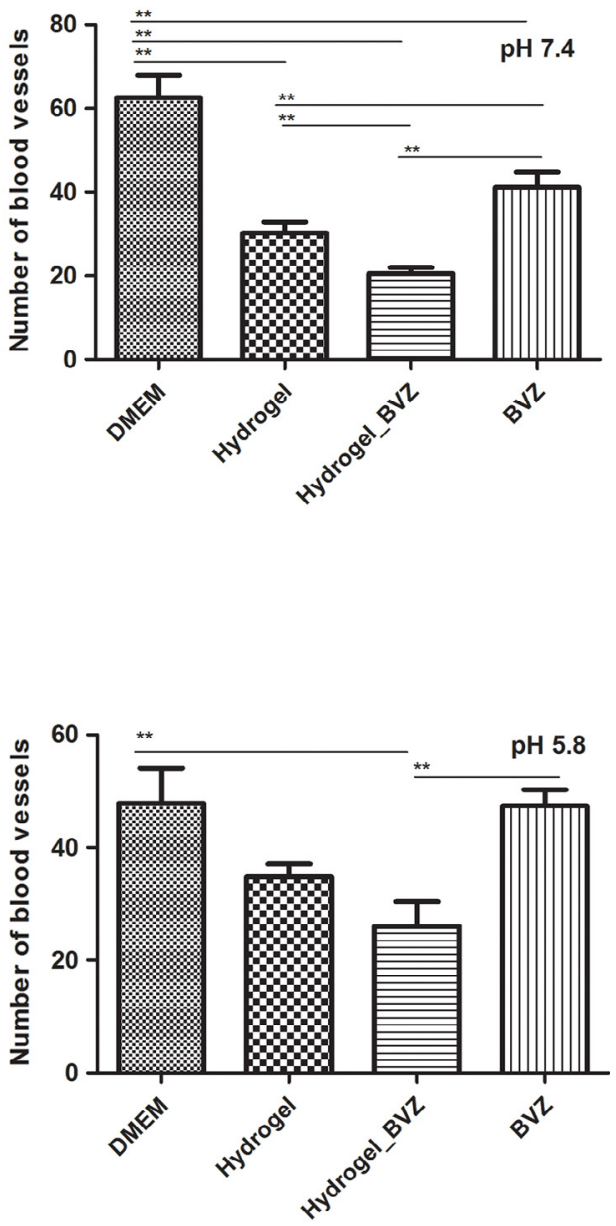

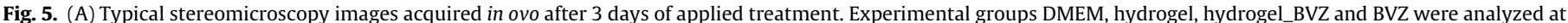

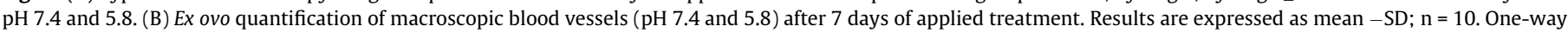

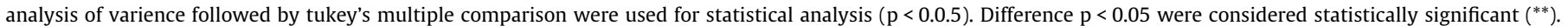

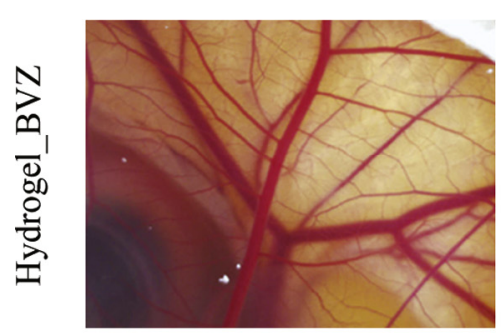

Day 1

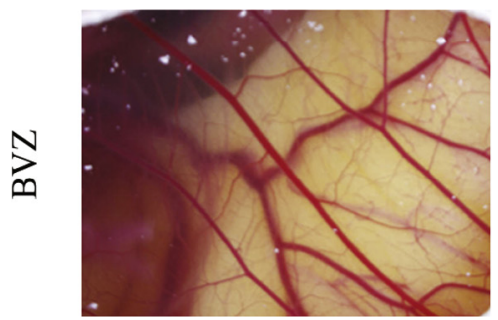

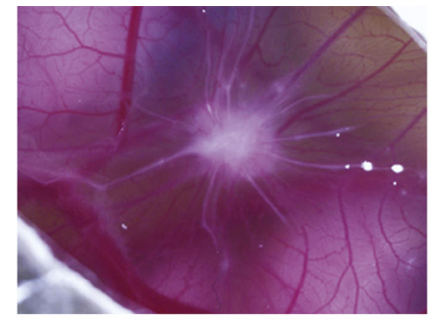

Day 3

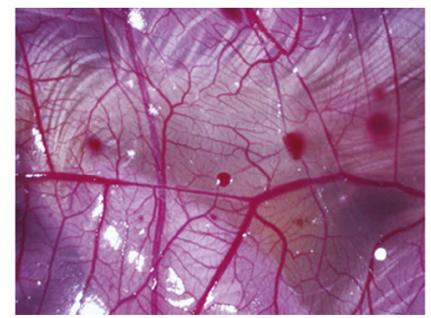

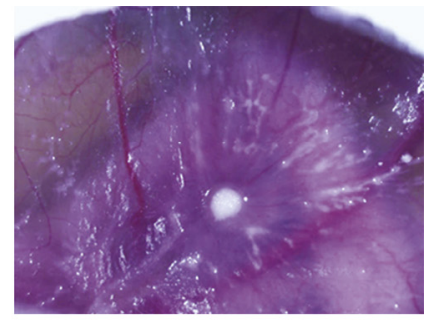

Day 7

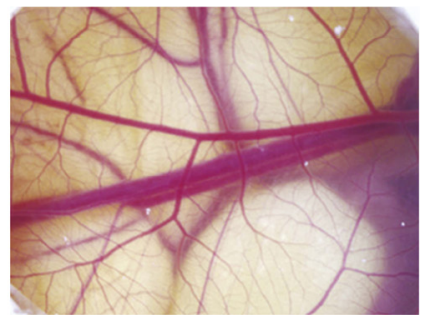

Fig. 6. Stereomicroscopy images acquired in ovo show vascular changes over the experimental procedure. Groups treated with hydrogel_BVZ and BVZ at pH 7.4 . 
angiogenic effect compared to commercial available anti-VEGF drug for both studied $\mathrm{pH}$ values, which include extreme conditions encountered at the tumor environment.

\subsection{Analysis of tumor development and progression treated by hydrogel_BVZ}

Implantation of U251 tumor cells $(2 \times 106$ cells in $20 \mathrm{~mL}$ DMEM medium) was performed to create a microtumor that would allow the analysis of system anti-angiogenic activity together with tumor development and progression by measuring tumor area and perimeter. Fig. 7A show pictures taken ex ovo for eggs treated with hydrogel_BVZ and eggs that received no treatment after 5 days of applied therapy. It can be noticed that the anti-angiogenic therapy induced blood vessel disorganization and inhibition of the ingrowth of new vessels, promoting a significant reduction in vascular density (Fig.7A).

Results of blood vessel counts after CAM excision (Fig.7B) showed a tendency for blood vessels reduction $( \pm 30 \%)$ when the anti-angiogenic treatment (hydrogel_BVZ) was applied. Fig. 7C depicts the tumor areas and perimeters at two different moments: day 1 represents tumor dimensions before treatment and day 5 relates to tumor measurements 4 days post anti-angiogenic therapy. As control, a group of eggs did not receive any treatment. In general, there was a propensity to a decrease in tumor size when hydrogel_BVZ were applied. Anti-VEGF treatment appears to promote tumor reduction in about $50 \%$ compared to the untreated group. However, further investigation remains required to support these results.

Immunohistochemistry evaluation of histological samples, especially the microscopic identification of blood vessels, provides valuable and useful qualitative and quantitative information to study angiogenesis [54]. Histological analysis was performed on microtumor sections. Chick blood vessels were labeled with biotinylated Sambucus Nigra lectin (SNL-lectin) to highlight regions containing blood vessels. Light microscopy photographs of the immunohistochemical staining from excised CAM contain- ing microtumors (Fig.7A) indicates that the control group possesses a higher number of microscopic blood vessels compared to experimental groups that received hydrogel_BVZ treatment. Furthermore, the control group appears to have high degree of blood vessel organization.

Taken together, the CAM model provides valuable insights into physiological and histological vascular system responses to applied therapy. Moreover, in vivo data strongly suggest that BVZ loaded hydrogels have increased anti-angiogenic activity and might display anti-neoplastic effects in extreme $\mathrm{pH}$ values encountered for solid tumors.

\section{Conclusions}

The use of drug delivery platforms to optimize therapeutic effect in pathological processes such as cancer is undoubtedly promising and should be specifically designed considering pathologic features. This concept provides adjustment between effects and interactions including several research areas to accomplish material self-assembly and stimulation of spontaneous processes.

In this paper, we successfully designed an innovative protein loaded hydrogel delivery system for localized anti-VEGF cancer therapy. This system would allow local application in a minimally invasive manner, refilling the formation of drug depots for slow and continuous protein release to the tumor and surrounding tissues, in addition to provide drug stability, especially in acid environments. The CAM assay demonstrated that BVZ has pronounced anti-angiogenic activity when loaded into hydrogel independently of $\mathrm{pH}$ (5.8 and 7.4). Furthermore, this system might provide an anti-neoplastic effect. Since these studied values represent extreme conditions encountered in the tumor environment, we anticipated that the developed systems have potential to be applied in a variety of solid tumors.

\section{Conflicts of interest}

The authors declare no competing financial interests.

\section{A}
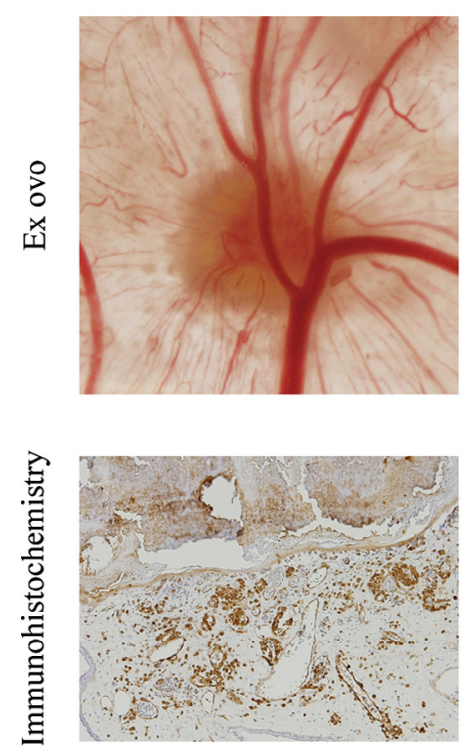

Hydrogel_BVZ
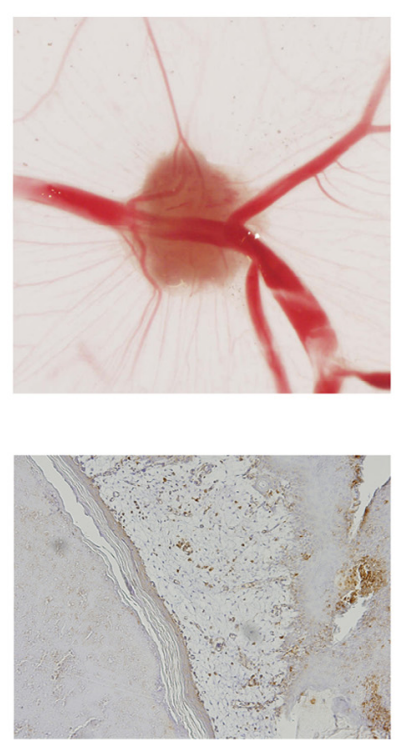

B

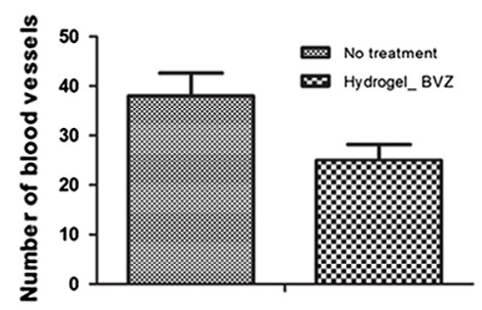

$\mathrm{C}$

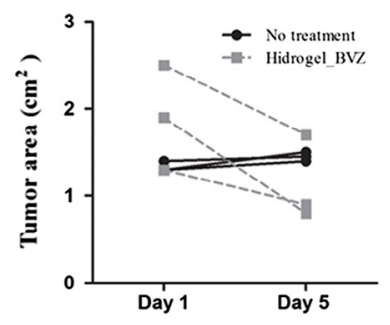

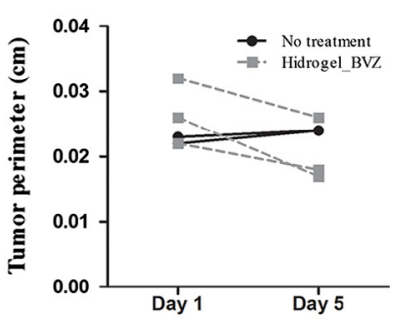

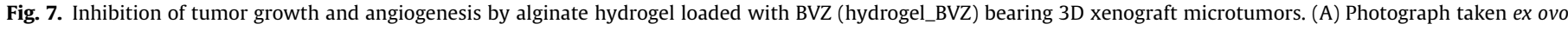

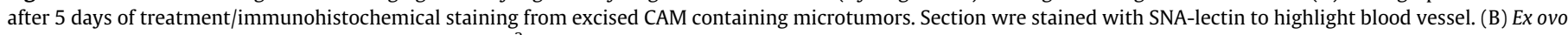

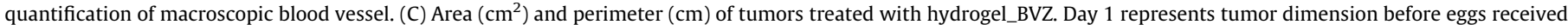

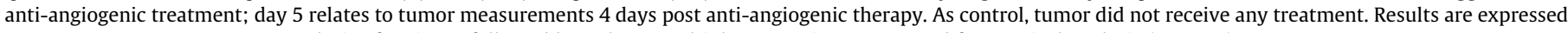
as mean -SD; $n=3$. One-way analysis of varience followed by Tukey's multiple comparison were used for stastical analysis ( $p<0.05$ ). 


\section{Author information}

The manuscript was written through contributions of all authors, equally. All authors have given approval to the final version of the manuscript.

\section{Acknowledgements}

This work was financially supported by the Brazilian Fundação de Amparo e Pesquisa do Estado de São Paulo (FAPESP), Coordenação de Aperfeiçoamento de Pessoal de Nível Superior (CAPES) and Conselho Nacional de Desenvolvimento Científico e Tecnológico (CNPq). Additionally, this article has been developed under the scope of the project NORTE-01-0145-FEDER-000013, supported by the Northern Portugal Regional Operational Programme (NORTE 2020), under the Portugal 2020 Partnership Agreement, through the European Regional Development Fund (FEDER) Project PTDC/SAU-TOX/114549/2009 - FCOMP-01-0124FEDER-016057, through the Competitiveness Factors Operational Programme (COMPETE), and by National funds, through the Foundation for Science and Technology (FCT), under the scope of the project POCI-01-0145-FEDER-007038.

\section{References}

[1] H. Yu, A. Jiang, J. Shen, Prevalence and predictors of compassion fatigue burnout and compassion satisfaction among oncology nurses: a crosssectional survey, Int. J. Nurs. Stud. 57 (2016) 28-38.

[2] J.S. Andrew, E.J. Anglin, E.C. Wu, M.Y. Chen, L. Cheng, W.R. Freeman, M.J. Sailor, Sustained release of a monoclonal antibody from electrochemically prepared mesoporous silicon oxide, Advan. Funct. Mater. 20 (2010) 4168-4174.

[3] T.G. Burish, D.M. Tope, Psychological techniques for controlling the adverse side effects of cancer chemotherapy: findings from a decade of research, J. Pain Symptom Manage. 7 (1992) 287-301.

[4] C.K. Pan, C. Durairaj, U.B. Kompella, O. Agwu, S.C. Oliver, H. Quiroz-Mercado, N. Mandava, J.L. Olson, Comparison of long-acting bevacizumab formulations in the treatment of choroidal neovascularization in a rat model, J. Ocul. Pharmacol. Ther. 27 (2011) 219-224.

[5] D.W. Grainger, Controlled-release and local delivery of therapeutic antibodies Expert Opin. Biol. Ther. 4 (2004) 1029-1044.

[6] F.C. Carvalho, M.L. Campos, R.G. Peccinini, M.P. Gremiao, Nasal administration of liquid crystal precursor mucoadhesive vehicle as an alternative antiretroviral therapy, Eur. J. Pharm. Biopharm. 84 (2013) 219-227.

[7] N. Ferrara, H.P. Gerber, J. LeCouter, The biology of VEGF and its receptors, Nat. Med. 9 (2003) 669-676.

[8] V. Miranda-Goncalves, M. Honavar, C. Pinheiro, O. Martinho, M.M. Pires, C. Pinheiro, M. Cordeiro, G. Bebiano, P. Costa, I. Palmeirim, R.M. Reis, F. Baltazar Monocarboxylate transporters (MCTs) in gliomas: expression and exploitation as therapeutic targets, Neuro. Oncol. 15 (2013) 172-188.

[9] T. Tagami, T. Suzuki, M. Matsunaga, K. Nakamura, N. Moriyoshi, T. Ishida, H. Kiwada, Anti-angiogenic therapy via cationic liposome-mediated systemic siRNA delivery, Int. J. Pharm. 422 (2012) 280-289.

[10] J. Folkman, Tumor Angiogenesis: therapeutic implications, N. Engl. J. Med. 285 (1971) 1182-1186.

[11] L.D. Sasich, S.R. Sukkari, The US FDAs withdrawal of the breast cancer indication for Avastin bevacizumab, Saudi Pharm. J. 20 (2012) 381-385.

[12] A.M. Scott, J.D. Wolchok, L.J. Old, Antibody therapy of cancer, Nat. Rev. Cancer. 12 (2012) 278-287.

[13] N. Ferrara, Vascular endothelial growth factor as a target for anticancer therapy, Oncologist 9 (2004) 2-10.

[14] J.B. Gunther, M.M. Altaweel, Bevacizumab (Avastin) for the treatment of ocular disease, Surv. Ophthalmol. 54 (2009) 372-400.

[15] K.O. Chu, D.T. Liu, K.P. Chan, Y.P. Yang, G.H. Yam, M.S. Rogers, C.P. Pang, Quantification and structure elucidation of in vivo bevacizumab modification in rabbit vitreous humor after intravitreal injection, Mol. Pharm. 9 (2012) $3422-3433$.

[16] A. Messori, Avastin-Lucentis: off-label and surroundings, Recenti. Prog. Med. 105 (2014) 137-140.

[17] J.J.K. Derwent, W.F. Mieler, Thermoresponsive hydrogels as a new ocular drug delivery platform to the posterior segment of the eye, Trans. Am. Ophthalmol. Soc. 106 (2008) 206-213.

[18] C.H. Wang, Y.S. Hwang, P.R. Chiang, C.R. Shen, W.H. Hong, G.H. Hsiue, Extended release of bevacizumab by thermosensitive biodegradable and biocompatible hydrogel, Biomacromolecules 13 (2012) 40-48.

[19] F. Li, B. Hurley, Y. Liu, B. Leonard, M. Griffith, Controlled release of bevacizumab through nanospheres for extended treatment of age-related macular degeneration, Open Ophthalmol. J. 6 (2012) 54-58.
[20] H.-J. Yoon, W.-D. Jang, Polymeric supramolecular systems for drug delivery, J. Mater. Chem. 20 (2010) 211-222.

[21] D. Schweizer, T. Serno, A. Goepferich, Controlled release of therapeutic antibody formats, Eur. J. Pharm. Biopharm. 88 (2014) 291-309.

[22] K. Krukiewicz, J.K. Zak, Biomaterial-based regional chemotherapy: local anticancer drug delivery to enhance chemotherapy and minimize its sideeffects, Mater. Sc. Eng. C Mater. Biol. Appl. 62 (2016) 927-942.

[23] K. Dave, R. Averineni, P. Sahdev, O. Perumal, Transpapillary drug delivery to the breast, PLoS One 9 (2014) e115712.

[24] J.D. Byrne, M.R. Jajja, A.T. O'Neill, L.R. Bickford, A.W. Keeler, N. Hyder, K. Wagner, A. Deal, R.E. Little, R.A. Moffitt, C. Stack, M. Nelson, C.R. Brooks, W. Lee, J.C. Luft, M.E. Napier, D. Darr, C.K. Anders, R. Stack, J.E. Tepper, A.Z. Wang, W.C. Zamboni, J.J. Yeh, J.M. DeSimone, Local iontophoretic administration of cytotoxic therapies to solid tumors, Sci Transl Med, 7 (2015) 273ra214.

[25] Y. Li, J. Wang, M.G. Wientjes, J.L. Au, Delivery of nanomedicines to extracellular and intracellular compartments of a solid tumor, Adv. Drug Deliv. Rev. 64 (2012) 29-39.

[26] L. Tian, Y.H. Bae, Cancer nanomedicines targeting tumor extracellular pH, Colloids Surf. B Biointerfaces 99 (2012) 116-126.

[27] J.W. Choi, S.J. Jung, D. Kasala, J.K. Hwang, J. Hu, Y.H. Bae, C.O. Yun, pH-sensitive oncolytic adenovirus hybrid targeting acidic tumor microenvironment and angiogenesis, J. Control Releas. 205 (2015) 134-143.

[28] I.F. Tannock, D. Rotin, Acid pH in tumors and its potential for therapeutic exploitation, Cancer res. 49 (1989) 4373-4384.

[29] K. Engin, D.B. Leeper, J.R. Cater, A.J. Thistlethwaite, L. Tupchong, J.D. McFarlane, Extracellular $\mathrm{pH}$ distribution in human tumours, Int. J. Hyperthermia 11 (1995) 211-216

[30] Y. Brudno, E.A. Silva, C.J. Kearney, S.A. Lewin, A. Miller, K.D. Martinick, M. Aizenberg, D.J. Mooney, Refilling drug delivery depots through the blood, Proc. Natl. Acad. Sci. USA 111 (2014) 12722-12727.

[31] S. Ishii, J. Kaneko, Y. Nagasaki, Development of a long-acting, protein-loaded, redox-active, injectable gel formed by a polyion complex for local protein therapeutics, Biomaterials 84 (2016) 210-218.

[32] H.J. Jhan, J.J. Liu, Y.C. Chen, D.Z. Liu, M.T. Sheu, H.O. Ho, Novel injectable thermosensitive hydrogels for delivering hyaluronic acid-doxorubicin nanocomplexes to locally treat tumors, Nanomedicine (Lond) 10 (2015) 1263-1274.

[33] L. Li, J. Gu, J. Zhang, Z. Xie, Y. Lu, L. Shen, Q. Dong, Y. Wang, Injectable and biodegradable $\mathrm{pH}$-responsive hydrogels for localized and sustained treatment of human fibrosarcoma, ACS Appl. Mater. Interfaces 7 (2015) 8033-8040.

[34] J.M. Olbrich, P.L. Tate, J.T. Corbett, J.M. Lindsey 3rd, S.D. Nagatomi, W.S. Shalaby, S.W. Shalaby, Injectable in situ forming controlled release implant composed of a poly-ether-ester-carbonate and applications in the field of chemotherapy, J. Biomed. Mater. Res. A 100 (2012) 2365-2372.

[35] T.R. Hoare, D.S. Kohane, Hydrogels in drug delivery: progress and challenges, Polym. 49 (2008) 1993-2007.

[36] C.T. Tsao, F.M. Kievit, A. Ravanpay, A.E. Erickson, M.C. Jensen, R.G. Ellenbogen, M. Zhang, Thermoreversible poly(ethylene glycol)-g-chitosan hydrogel as a therapeutic T lymphocyte depot for localized glioblastoma immunotherapy, Biomacromolecules 15 (2014) 2656-2662.

[37] Y. Matsumura, T. Hamaguchi, T. Ura, K. Muro, Y. Yamada, Y. Shimada, K. Shirao, T. Okusaka, H. Ueno, M. Ikeda, N. Watanabe, Phase I clinical trial and pharmacokinetic evaluation of NK911, a micelle-encapsulated doxorubicin, Br J Cancer, 91 (2004) 1775-1781.

[38] A. López Córdoba, L. Deladino, M. Martino, Effect of starch filler on calciumalginate hydrogels loaded with yerba mate antioxidants, Carbohydr. Polym. 95 (2013) 315-323.

[39] M.A. Abd El-Ghaffar, M.S. Hashem, M.K. El-Awady, A.M. Rabie, pH-sensitive sodium alginate hydrogels for riboflavin controlled release, Carbohydr Polym, 89 (2012) 667-675.

[40] D. Zhong, X. Huang, H. Yang, R. Cheng, New insights into viscosity abnormality of sodium alginate aqueous solution, Carbohydr. Polym. 81 (2010) 948-952.

[41] D. Schweizer, K. Schonhammer, M. Jahn, A. Gopferich, Protein-polyanion interactions for the controlled release of monoclonal antibodies, Biomacromolecules 14 (2013) 75-83.

[42] H. Grasdalen, B. Larsen, O. Smidsrød, A p.m.r. study of the composition and sequence of uronate residues in alginates, Carbohydr. Res. 68 (1979) 23-31.

[43] H. Grasdalen, High-field, ${ }^{1}$ H-n.m.r. spectroscopy of alginate: sequential structure and linkage conformations, Carbohydr. Res. 118 (1983) 255-260.

[44] G. Bohm, R. Muhr, R. Jaenicke, Quantitative analysis of protein far UV circular dichroism spectra by neural networks, Protein Eng. 5 (1992) 191-195.

[45] E. Ansorena, P. De Berdt, B. Ucakar, T. Simón-Yarza, D. Jacobs, O. Schakman, A. Jankovski, R. Deumens, M.J. Blanco-Prieto, V. Préat, A.d. Rieux, injectable alginate hydrogel loaded with GDNF promotes functional recovery in a hemisection model of spinal cord injury, Int. J. Pharm. 455 (2013) 148-158.

[46] N. El Kechai, A. Bochot, N. Huang, Y. Nguyen, E. Ferrary, F. Agnely, Effect of liposomes on rheological and syringeability properties of hyaluronic acid hydrogels intended for local injection of drugs, Int. J. Pharm. 487 (2015) 187196.

[47] D.S. Jones, A.D. Woolfson, A.F. Brown, M.J. O’Neill, Mucoadhesive, syringeable drug delivery systems for controlled application of metronidazole to the periodontal pocket: in vitro release kinetics, syringeability, mechanical and mucoadhesive properties, J. Control. Releas. 49 (1997) 71-79.

[48] M.L. Bruschi, D.S. Jones, H. Panzeri, M.P.D. Gremião, O. de Freitas, E.H.G. Lara, Semisolid systems containing propolis for the treatment of periodontal disease 
in: Vitro release kinetics, syringeability, rheological, textural, and mucoadhesive properties, J. Pharm. Sc. 96 (2007) 2074-2089.

[49] V. Burckbuchler, G. Mekhloufi, A.P. Giteau, J.L. Grossiord, S. Huille, F. Agnely, Rheological and syringeability properties of highly concentrated human polyclonal immunoglobulin solutions, Eur. J. Pharm. Biopharm. 76 (2010) 351-356.

[50] R. Voight, Pharmazeutische Technologie: für Studium und Beruf, Deutscher Apotheker, Stuttgart, 2000.

[51] B.S. Cury, A.D. Castro, S.I. Klein, R.C. Evangelista, Modeling a system of phosphated cross-linked high amylose for controlled drug release. Part 2: physical parameters, cross-linking degrees and drug delivery relationships, Int. J. Pharm. 371 (2009) 8-15.

[52] J. Ceulemans, I. Vinckier, A. Ludwig, The use of xanthan gum in an ophthalmic liquid dosage form: rheological characterization of the interaction with mucin, J. Pharm. Sci. 91 (2002) 1117-1127.

[53] A. Saxena, M. Kaloti, H.B. Bohidar, Rheological properties of binary and ternary protein-polysaccharide co-hydrogels and comparative release kinetics of salbutamol sulphate from their matrices, Int. J. Biol. Macromol. 48 (2011) 263-270.

[54] J. Silva-Correia, V. Miranda-Goncalves, A.J. Salgado, N. Sousa, J.M. Oliveira, R.M. Reis, R.L. Reis, Angiogenic potential of gellan-gum-based hydrogels for application in nucleus pulposus regeneration: in vivo study, Tissue Eng. Part A 18 (2012) 1203-1212.

[55] O. Martinho, S. Granja, T. Jaraquemada, C. Caeiro, V. Miranda-Gonçalves, M. Honavar, P. Costa, M. Damasceno, M.R. Rosner, J.M. Lopes, R.M. Reis, Downregulation of RKIP is associated with poor outcome and malignant progression in gliomas, PLoS ONE 7 (2012) e30769.

[56] O. Martinho, R. Silva-Oliveira, V. Miranda-Goncalves, C. Clara, J.R. Almeida, A.L. Carvalho, J.T. Barata, R.M. Reis, In Vitro and In Vivo analysis of RTK inhibitor efficacy and identification of its novel targets in glioblastomas, Transl. Oncol. 6 (2013) 187-196.

[57] D. Ribatti, A. Vacca, L. Roncali, F. Dammacco, The chick embryo chorioallantoic membrane as a model for in vivo research on angiogenesis, Int. J. Dev. Biol. 40 (1996) 1189-1197.

[58] U. Bilati, E. Allémann, E. Doelker, Strategic approaches for overcoming peptide and protein instability within biodegradable nano- and microparticles, Eur. J. Pharm. Biopharm. 59 (2005) 375-388.

[59] P. Tyagi, M. Barros, J.W. Stansbury, U.B. Kompella, Light-activated, in situ forming gel for sustained suprachoroidal delivery of bevacizumab, Mol. Pharm. 10 (2013) 2858-2867.

[60] J. Song, F.Y. Wu, Y.Q. Wan, L.H. Ma, Ultrasensitive turn-on fluorescent detection of trace thiocyanate based on fluorescence resonance energy transfer, Talanta 132 (2015) 619-624.

[61] C.L. Cooper, P.L. Dubin, A.B. Kayitmazer, S. Turksen, Polyelectrolyte-protein complexes, Curr. Opin. Colloid Interface Sci. 10 (2005) 52-78.

[62] R.M. Ionescu, J. Vlasak, C. Price, M. Kirchmeier, Contribution of variable domains to the stability of humanized IgG1 monoclonal antibodies, J. Pharm. Sci. 97 (2008) 1414-1426.

[63] O.N. Ivinova, V.A. Izumrudov, V.I. Muronetz, I.Y. Galaev, B. Mattiasson, Influence of complexing polyanions on the thermostability of basic proteins, Macromol. Biosci. 3 (2003) 210-215.

[64] T. Derrick, A.O. Grillo, S.N. Vitharana, L. Jones, J. Rexroad, A. Shah, M. Perkins, T. M. Spitznagel, C.R. Middaugh, Effect of polyanions on the structure and stability of repifermin keratinocyte growth factor-2, J. Pharm. Sci. 96 (2007) 761-776.

[65] O. Smidsrød, G. Skjåk-Braek, Alginate as immobilization matrix for cells, Trends Biotechnol. 8 (1990) 71-78.

[66] A.D. Augst, H.J. Kong, D.J. Mooney, Alginate hydrogels as biomaterials, Macromol. Biosci. 6 (2006) 623-633.

[67] S.T. Moe, K.I. Draget, G. Skjåk-Bræk, O. Simdsrød, Temperature dependence of the elastic modulus of alginate gels, Carbohydr. Polym. 19 (1992) 279-284.

[68] W. Rungseevijitprapa, R. Bodmeier, Injectability of biodegradable in situ forming microparticle systems ISM, Eur. J. Pharm. Sci. 36 (2009) 524-531.

[69] P.-E. Le Renard, O. Jordan, A. Faes, A. Petri-Fink, H. Hofmann, D. Rüfenacht, F. Bosman, F. Buchegger, E. Doelker, The in vivo performance of magnetic particle-loaded injectable, in situ gelling, carriers for the delivery of local hyperthermia, Biomaterials 31 (2010) 691-705.
[70] P. Agulhon, M. Robitzer, J.-P. Habas, F. Quignard, Influence of both cation and alginate nature on the rheological behavior of transition metal alginate gels, Carbohydr. Polym. 112 (2014) 525-531.

[71] Y. Yang, O.H. Campanella, B.R. Hamaker, G. Zhang, Z. Gu, Rheological investigation of alginate chain interactions induced by concentrating calcium cations, Food Hydrocoll. 30 (2013) 26-32.

[72] I.A. Alsarra, A.Y. Hamed, F.K. Alanazi, S.H. Neau, Rheological and mucoadhesive characterization of poly(vinylpyrrolidone) hydrogels designed for nasa mucosal drug delivery, Arch. Pharm. Res. 34 (2011) 573-582.

[73] S. Jabeen, M. Maswal, O.A. Chat, G.M. Rather, A.A. Dar, Rheological behavior and Ibuprofen delivery applications of $\mathrm{pH}$ responsive composite alginate hydrogels, Colloids Surf. B Biointerfaces 139 (2016) 211-218.

[74] G. Calixto, A.C. Yoshii, H. Rocha e Silva, B. Stringhetti Ferreira Cury, M. Chorilli, Polyacrylic acid polymers hydrogels intended to topical drug delivery: preparation and characterization, Pharm Dev Techno, 0 (2014) 1-7.

[75] Q. Wang, X. Xie, X. Zhang, J. Zhang, A. Wang, Preparation and swelling properties of pH-sensitive composite hydrogel beads based on chitosan-g-poly (acrylic acid)/vermiculite and sodium alginate for diclofenac controlled release, Int. J. Biol. Macromol. 46 (2010) 356-362.

[76] P. Colombo, R. Bettini, P. Santi, N.A. Peppas, Swellable matrices for controlled drug delivery: gel-layer behaviour, mechanisms and optimal performance Pharm. Sci. Technolo. Today 3 (2000) 198-204.

[77] M.S. Kim, S.J. Park, B.K. Gu, C.-H. Kim, Ionically crosslinked alginatecarboxymethyl cellulose beads for the delivery of protein therapeutics, Appl. Surf. Sci 262 (2012) 28-33.

[78] M.R. de Moura, M.R. Guilherme, G.M. Campese, E. Radovanovic, A.F. Rubira, E. C. Muniz, Porous alginate-Ca2 + hydrogels interpenetrated with PNIPAAm networks: interrelationship between compressive stress and pore morphology, Eur. Polym. J. 41 (2005) 2845-2852.

[79] A.E. Nel, L. Madler, D. Velegol, T. Xia, E.M.V. Hoek, P. Somasundaran, F. Klaessig V. Castranova, M. Thompson, Understanding biophysicochemical interactions at the nano-bio interface, Nature Mater. 8 (2009) 543-557.

[80] P.C.A. Rodrigues, U. Beyer, P. Schumacher, T. Roth, H.H. Fiebig, C. Unger, L. Messori, P. Orioli, D.H. Paper, R. Mülhaupt, F. Kratz, Acid-sensitive polyethylene glycol conjugates of doxorubicin: preparation, in vitro efficacy and intracellular distribution, Bioorg. Med. Chem. 7 (1999) 2517-2524.

[81] P.C. Rodrigues, U. Beyer, P. Schumacher, T. Roth, H.H. Fiebig, C. Unger, L. Messori, P. Orioli, D.H. Paper, R. Mulhaupt, F. Kratz, Acid-sensitive polyethylene glycol conjugates of doxorubicin: preparation, in vitro efficacy and intracellular distribution, Bioorg. Med. Chem. 7 (1999) 2517-2524.

[82] S. Ramakrishnan, T.A. Olson, V.L. Bautch, D. Mohanraj, Vascular endothelia growth factor-toxin conjugate specifically inhibits KDR/flk-1-positive endothelial cell proliferation in vitro and angiogenesis in vivo, Cancer Res. 56 (1996) 1324-1330.

[83] D. Mandracchia, G. Tripodo, A. Trapani, S. Ruggieri, T. Annese, T. Chlapanidas G. Trapani, D. Ribatti, Inulin based micelles loaded with curcumin or celecoxib with effective anti-angiogenic activity, Eur. J. Pharm. Sci. 93 (2016) 141-146.

[84] F. Ramazani, C. Hiemstra, R. Steendam, F. Kazazi-Hyseni, C.F. Van Nostrum, G. Storm, F. Kiessling, T. Lammers, W.E. Hennink, R.J. Kok, Sunitinib microspheres based on [PDLLA-PEG-PDLLA]-b-PLLA multi-block copolymers for ocular drug delivery, Eur. J. Pharm. Biopharm. 95 (Part B) (2015) 368-377.

[85] A. Vargas, M. Zeisser-Labouèbe, N. Lange, R. Gurny, F. Delie, The chick embryo and its chorioallantoic membrane (CAM) for the in vivo evaluation of drug delivery systems, Adv. Drug. Deliv. Rev. 59 (2007) 1162-1176.

[86] Y.-J. Yuan, K. Xu, W. Wu, Q. Luo, J.-L. Yu, Application of the chick embryo chorioallantoic membrane in neurosurgery disease, Int. J. Med. Sci. 11 (2014) $1275-1281$.

[87] J. Borges, F.T. Tegtmeier, N.T. Padron, M.C. Mueller, E.M. Lang, G.B. Stark Chorioallantoic membrane angiogenesis model for tissue engineering: a new twist on a classic model, Tissue Eng. Part A 9 (2003) 441-450.

[88] H. Chen, C.S. Wang M. Li, E. Sanchez, J. Li, A. Berenson, E. Wirtschafter J. Wang J. Shen, Z. Li, B. Bonavida, J.R. Berenson, A novel angiogenesis model for screening anti-angiogenic compounds: the chorioallantoic membrane/feather bud assay, Int. J. Oncol. 37 (2010) 71-79.

[89] K. Lee, D.Z. Oian, S. Rey, H. Wei, J.O. Liu, G.L. Semenza, Anthracycline chemotherapy inhibits HIF-1 transcriptional activity and tumor-induced mobilization of circulating angiogenic cells, Proc. Natl. Acad. Sci. USA 106 (2009) 2353-2358. 